\title{
Finite Element Modelling of Laser Stitch Welding Joints for Structural Dynamic Prediction
}

\author{
M. A. S. Aziz Shah, M. A. Yunus*, M. N. Abdul Rani, M. S. Mohd Zin, and \\ W. I. I. Wan Iskandar Mirza
}

Structural Dynamics Analysis and Validation (SDAV), Faculty of Mechanical Engineering, Universiti Teknologi MARA (UiTM), 40450 Shah Alam, Selangor, Malaysia

*Email: mayunus@salam.uitm.edu.my

\begin{abstract}
Laser stitch welding is a joining technique that has been increasingly popular in automotive industries, such as in the manufacturing and assembling of the car's body-inwhite (BiW) due to its advantages over the resistance spot weld, such as low heat application and high strength weld. The dynamic behaviour of a laser stitch welded structure is relatively difficult to predict accurately due to local parameters being induced during the laser welding process, such as heat affected zone (HAZ) and residual stress in the welded structure. This paper presents the idea of modelling the laser stitch weld by investigating different types of element connectors that can be used to represent laser stitch weld, such as rigid body element (RBE2), shell element (CQUAD4), bar element (CBAR) and area contact model (ACM2) format of element connectors. The accuracy of finite element models of laser stitch welded joints is compared in terms of natural frequencies and mode shapes with the experiment counterparts. The dynamic behaviour of the measured structure is obtained by using an impact hammer with free-free boundary conditions. It is found that the accuracy of the finite element models of the laser stitch welded structure highly depends on the involvement of residual stress and the heat affected zones that are generated from the welding process.
\end{abstract}

Keywords: Finite element model; dynamic behaviour; heat affected zone; laser stitch weld.

\section{INTRODUCTION}

In recent years, the laser stitch welding is extensively used to join thin metal sheets in producing the car's body-in-white (BiW) through the use of a laser. The laser provides a concentrated heat source to join the components of thin steel sheet by heating the components with high temperature. Therefore, no external material is added for joining purpose [1-3]. Due to that, the application of laser welding has become more preferable since it is able to produce a lightweight jointed structure.

The availability of numerous connecting joints in the car's BiW brings such a significant contribution towards structure integrity particularly the dynamic behaviour of the structure that influence the comfort ride of the car. Thus, it is important to understand the dynamic behaviour of a jointed structure due to laser welding so that the dynamic behaviour of the overall automotive structure can be predicted accurately [4-8]. However, to numerically model the structure jointed by laser welding for finite element (FE) analysis is very difficult, challenging and time consuming due to the involvement of 
uncertainties that are produced during the joining process, such as frictional damping, localised stiffness and heat affected zone (HAZ) on the joint itself [9-13].

There are several researches regarding the employment of suitable element connector to represent laser weld joints. However, most of the recent studies are only related to the modelling of laser spot welded joints. For instance, Husain et al. [14] had employed the CWELD connector for FE modelling of laser spot weld and the patch size was set to be 20 percent bigger than the nominal diameter of spot weld. In another research, Rani et al. [15] had proved the capability of CWELD to represent itself as the better element connector for laser spot welded structures in comparison to RBE2 and ACM2 elements. Furthermore, Yunus et al. [16] had presented the idea of FE modelling for laser stitch weld by employing a shell element.

Previously, many research works have been done in order to produce reliable and accurate models of laser spot weld joints using hat-plate components. It has been found that the most popular and reliable element connector to be used was CWELD [17-19]. However, in this work, the CWELD element connector was not considered as a laser stitch weld because of certain limitations it possesses. Theoretically, the diameter and the material properties of the true spot weld are required to be defined in CWELD elements. Moreover, CWELD elements are not suitable to be used for unrounded weld presentations such as seam weld or stitch weld, since it is only applicable for rounded welded geometry only. This limitation makes the CWELD element not suitable to be implemented in this study.

Although several studies have been conducted, to the best of the knowledge of the authors, FE modelling of laser stitch welded structure for the investigation of dynamic behaviours is still lacking. Therefore, a continuous study to investigate FE model with potential element connectors to represent the laser welds joint needs to be conducted.

\section{DESCRIPTION OF STRUCTURE}

The structure that was used in this research is a simplified model of the car pillar structure that was made from thin steel sheet components and jointed by laser stitch welds as shown in Figure 1. The simplified structure is formed from two components which are hat-shape thin plate and flat-shape thin plate. Both components were fabricated from cold rolled milled steel sheets with nominal thickness of $1.5 \mathrm{~mm}$. The overall dimensions of the substructures are $564 \mathrm{~mm}$ in length, $110 \mathrm{~mm}$ in width and $40 \mathrm{~mm}$ in height. The substructures were connected by twenty laser stitch welds with $23 \mathrm{~mm}$ average length.

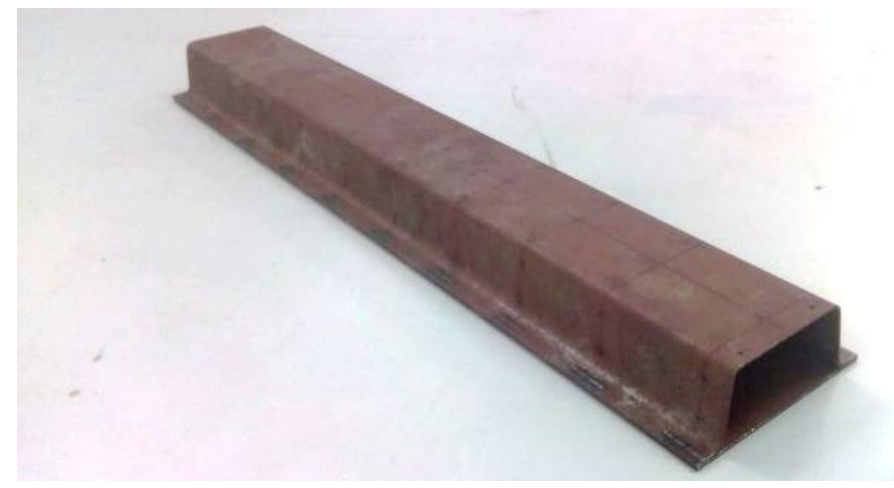

Figure 1. Laser stitch welded structure. 


\section{FINITE ELEMENT MODELLING FOR STRUCURAL DYNAMICS}

In this research, the laser stitch welded structure as shown in Figure 2 was constructed using finite element analysis software package. Finite element analysis is a method that involves the discretisation of the structure into small elements [20-24]. These small elements are then sent into nodes which contain the information of this analysis. Analysts use this technique to obtain a reliable predicted model to follow the design specification before proceeding to the manufacturing process. The normal mode analysis is used to predict the dynamic behaviours of the structure which are natural frequencies and mode shapes. These responses are obtained by solving the Eq. (1).

$\left(\mathbf{K}-\omega^{2} \mathbf{M}\right) \phi=0$

where, $\mathbf{K}$ is the symmetric matrices of stiffness, $\omega$ is the natural frequency, $\mathbf{M}$ is the symmetric matrices of mass, and $\phi$ is mode shape [25-27].

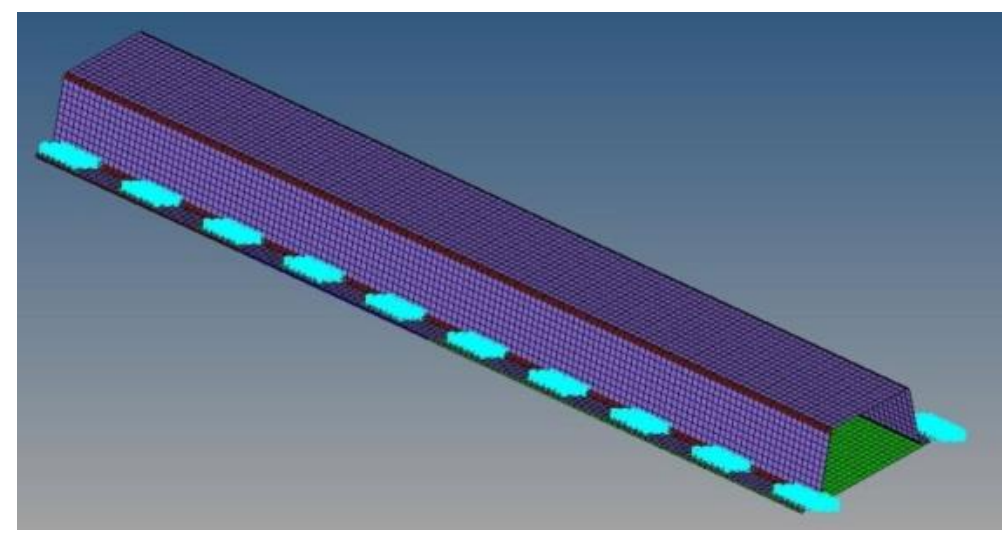

Figure 2. FE model of laser stitch welded structure.

\section{Finite Element Modelling Procedure}

The finite element model of laser stitch welded structure was developed based on the CAD model established from Coordinate Measuring Machine. The CAD model of the structure was constructed using CATIAV20 software. Prior to discretising the FE model with 2D shell element meshes, the geometries were converted into surface geometries using the mid-surface profile from the MSC.PATRAN. This step was crucial since only surface geometry was needed in 2D element meshing. Hence, the accelerometer used in the experiment should not exceed $1 / 10$ of the weight of the structure to be measured [28].

The finite element model of the structure was discretised starting with element size of $20 \mathrm{~mm}$ until the convergence of natural frequencies could be obtained. The outcome from mesh convergence test for the structure is shown in Figure 3. From the graphs, the natural frequencies of the structure were starting to converge from element size of $5 \mathrm{~mm}$ to element size of $1 \mathrm{~mm}$. However, the element size with $4 \mathrm{~mm}$ was much more suitable to select as mesh size since the distance between the profiles of laser weld and the flanges were also $4 \mathrm{~mm}$. Therefore, element size of $5 \mathrm{~mm}$ was not suitable since it did not represent the accurate dimension of structure. On the other hand, the element sizes of $3 \mathrm{~mm}$ to $1 \mathrm{~mm}$ were also not suitable because they only contributed to the high computational and CPU time due to the high overall elements and nodes number that 
needed to be solved. Table 1 shows the number of nodes and elements of the finite element model of a laser stitch welded structure.

Table 1. Number of nodes and elements of the structure.

\begin{tabular}{lcc}
\hline FE Model & Node & Element \\
\hline Hat Component & 6106 & 5922 \\
Plate Component & 4118 & 3948 \\
\hline
\end{tabular}

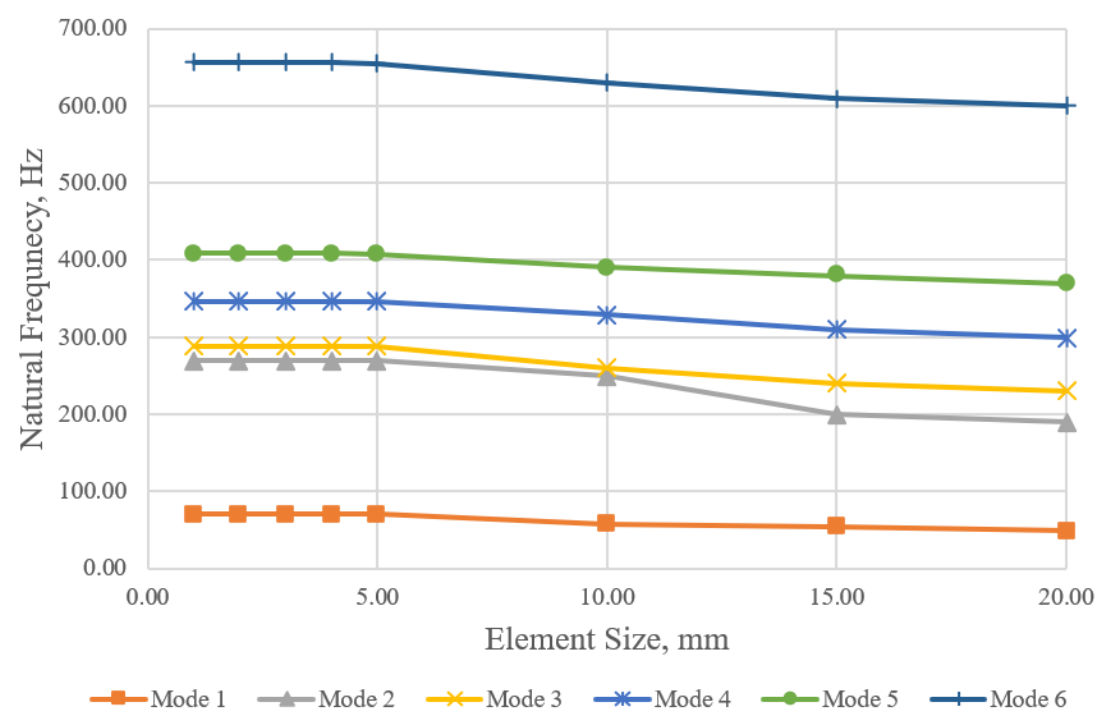

Figure 3. Convergence test for the laser stitch welded structure.

Meanwhile, for the solver, MSC.NASTRAN was used to analyse the natural frequencies and mode shapes in normal mode analysis. The frequencies of interest were set between $1 \mathrm{~Hz}$ to $1000 \mathrm{~Hz}$ and the first six modes were identified. The material properties of the model were followed by the nominal properties of mild steel as shown in Table 2 [29]. Load and constraint were not being assigned in order to simulate the freefree boundary conditions. The size of HAZ was set to be 70 percent bigger than the weld size.

There were four types element connectors used in order to represent the laser stitch weld - rigid body element (RBE2), shell element (CQUAD4), bar element (CBAR) and area contact model (ACM2). Therefore, four finite element models had been constructed, and the feasibility of these element connectors to represent as laser stitch welds were investigated.

Table 2. Nominal properties of mild steel [29].

\begin{tabular}{lc}
\hline Properties & Values \\
\hline Young's modulus $(E)$ & $210 \mathrm{GPa}$ \\
Poisson's ration $(v)$ & 0.30 \\
Density $(p)$ & $7400 \mathrm{~kg} / \mathrm{m}^{3}$ \\
\hline
\end{tabular}




\section{EXPERIMENTAL SETUP}

\section{Experimental Modal Analysis (EMA)}

Experimental modal analysis is a vibration testing technique that has been used to identify the dynamic behaviour of a laser stitch welded structure in terms of natural frequencies and mode shapes [30-34]. It obtains data by analysing the relationship of the excitation force given at certain points with the structural response in other points. These data are then compared to finite element analysis results so as to identify the degree of correlations between them. However, before the experiment is conducted, several factors, such as frequency bandwidth, suspension orientation, excitation method and number of accelerometers need to be considered from finite element analysis [35-37].

\section{Experimental Procedure}

The experimental modal analysis was conducted with free-free boundary conditions. The free-free boundary conditions become the most effective methods in modal analysis and was chosen in this work because the validation data with finite element model can easily be achieved without considering the effects of the boundary conditions [8, 37]. In order to achieve a free-free boundary conditions in this experimental work, four sets of nylon strings and springs were used to hang the structure from the clamps. Nylon string and soft spring were used to suspend the structure because they are very flexible and have very minimal effect particularly in damping on the test structure and can be neglected. The frequency bandwidth of interest of the test structure was set between $1 \mathrm{~Hz}$ to $1000 \mathrm{~Hz}$. This bandwidth range has been found to have sufficient global modes of interest in studies for automotive structure [38].

In this experiment, the dynamic behaviour of laser stitch welded structure was obtained using impact hammer and roving accelerometers. An impact hammer was used to excite the structure with one fixed reference accelerometer. Meanwhile, the remaining three accelerometers were roved around to completely measure the responses. The fixed accelerometer was needed at the excitation point as the guidance to ensure the response of the structure between each roving points were always consistent. It was important to carefully determine the excitation and measurement points of the structure. The number of excitation and measuring points depended on the frequency bandwidth of interest in order to excite all modes of interest and to obtain reliable mode shapes of the structure. This experiment also depended on the number of transducer and available test time. In order to reduce a possibility of losing any modes, the measuring points had been spread equally throughout the test structure. The accuracy of the test result completely depended on the way the accelerometer was installed. If too many accelerometers were installed, then there were chances for the structure to experience increments in mass and stiffness. Hence, the accelerometers used in the experiment were set not to exceed 1/10 of the weight of the structure to be measured [39]. Finally, the measured responses were extracted using LMS SCADAS system with PolyMAX curve-fitting procedure. 


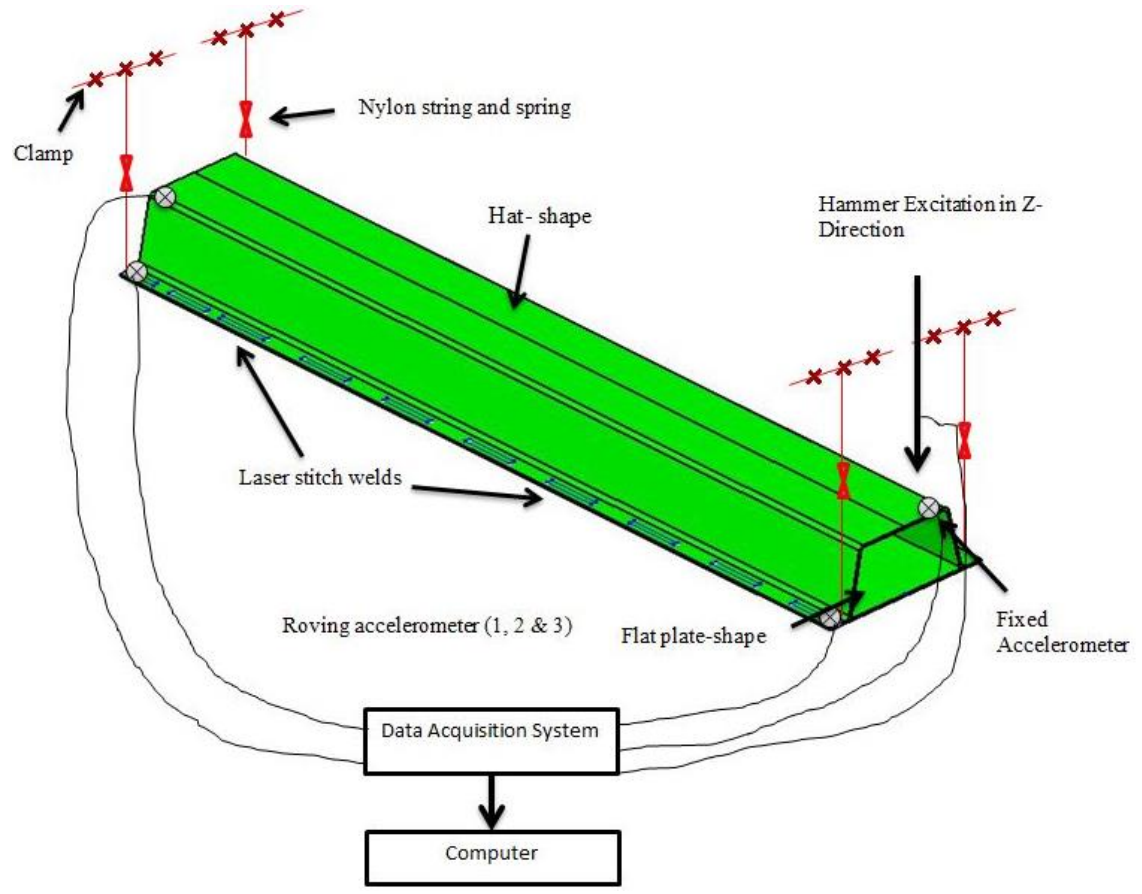

Figure 3. Schematic diagram of the experimental set-up.

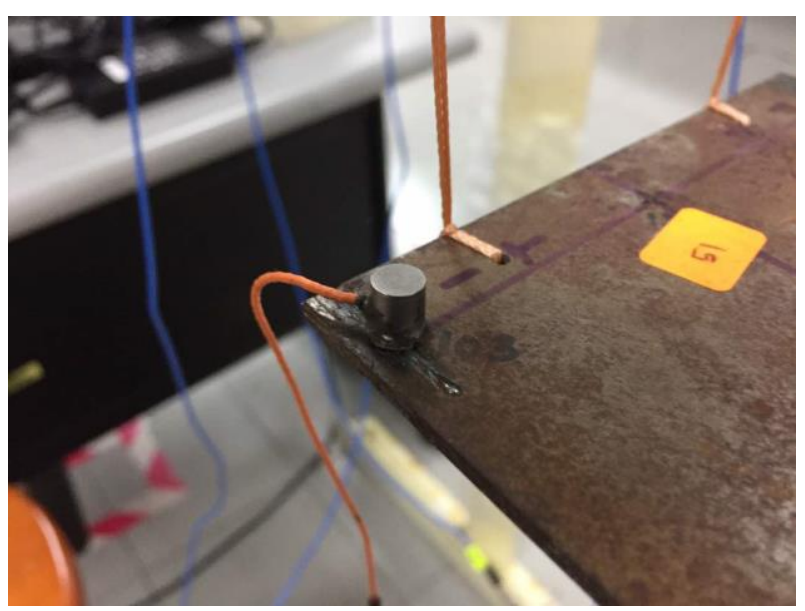

Figure 4. Accelerometer placement in the experiment.

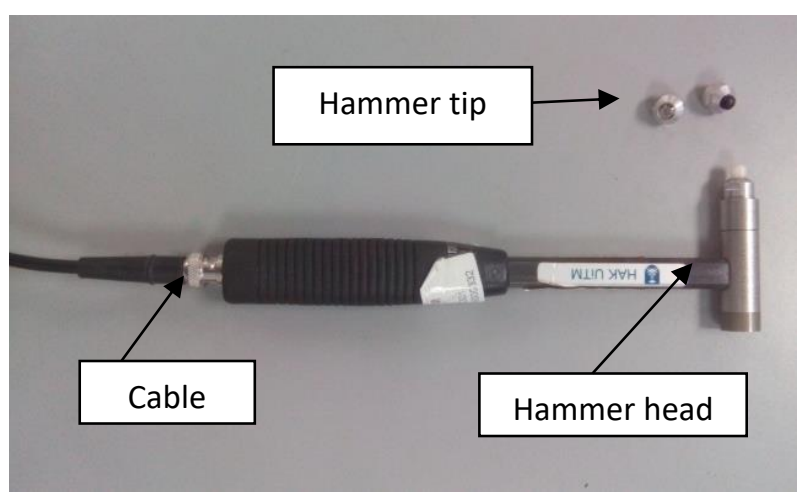

Figure 5. Impact hammer 


\section{RESULTS AND DISCUSSION}

In this study, the dynamic behaviour of laser stitch welded structure in terms of natural frequencies and mode shapes were obtained and compared experimentally and numerically to confirm the accuracy of the initial FE models. The four types of proposed element connectors namely RBE2, CBAR, CQUAD4 and ACM2 were compared in order to select the most suitable element connector to represent as laser stitch welds in the structure. The results from the comparisons of these element connectors are shows in Table 2. From the table, we can identify that the RBE2 based FE model has obtained the least total relative errors in terms of natural frequencies which is $8.38 \%$ compared to other three element connectors. The second least in total relative errors is ACM2 based FE model which $33.97 \%$, followed by CBAR based FE model with $36.71 \%$. The highest total relative errors obtained from the four initial FE models is CQUAD4 based FE model with $39.87 \%$. Despite obtaining the least total relative errors in terms of natural frequencies, the RBE2 element connector was not suitable to represent the laser stitch welds in the structure. This is because as shown in Table 2, there is a mode swapping issue in the predicted results of the RBE2 based FE model particularly between mode 2 and mode 3 . This mode swapping issue has given a major challenge in model updating due to the need to correct the predicted swapped modes [15]. The results suggest that there are considerable shortcomings in the RBE2 element connectors in representing the laser stitch welds in the structure. It was found that one of the significant shortcomings is that RBE2 element connectors provide inconsistent rigidity in 34 of the connections between the components of the structure. The inconsistent rigidity of RBE2 element connectors occur because of the properties of the element connector particularly its stiffness cannot be controlled or updated, and furthering it causes the element connectors to provide infinite stiffness to the structure [15]. Although the RBE2 based FE model provided low discrepancies against experiment results, it is worth noting that the RBE2 element connectors are realised by node to node connections, and consequently the actual connections of the welded areas cannot be obtained. Therefore, the results obtained from the RBE2 based FE model may not have any physical meanings and RBE2 element connectors cannot be used in confidence to represent the laser stitch welds.

From the CBAR based FE model results in Table 2, no mode swapping issue in predicted results were found, and the FE model managed to predict the natural frequencies of the structure consistently within the range of the frequency of interest. However, similar to RBE2 element connectors, the CBAR element connectors were realised by node to node connections and thus the connectors did not cover the whole actual welded areas. Moreover, to model the structure by using the CBAR element connectors, congruent meshes must be achieved [14]. It has been so difficult to obtain congruent meshes in the laser stitch welded structure because they contain 2 different shaped components such as hat shape and flat plate. The results obtained using CBAR based FE model may not represent the actual behaviour of the laser stitch welded structure. Therefore, it is worth noting that CBAR element connectors also cannot be used in confidence to represent the laser stitch welds.

The results in Table 2 also revealed that the CQUAD4 and ACM2 based FE models were suffering from underestimation of natural frequencies. The results shown has a good correlation of the natural frequencies between FE model and the experiment, achieved when ACM2 element connectors were employed to the laser stitch welded structure with the total relative errors of $33.97 \%$, as compared to the CQUAD elements in which the total relative errors is $39.87 \%$. The ACM2 element connectors are based on 
brick element, therefore they can represent and cover the actual welded areas [40]. It has been noted that the CQUAD4 and ACM2 based FE models managed to predict the mode dynamic behaviour without any mode swapping issue. Moreover, it has been found that, the CQUAD4 elements required coincident mesh surfaces, while the ACM2 element connectors can be used either for congruent or non-congruent meshes regardless of the surface condition [40]. Moreover, the ACM2 element connector contains the upgraded version of the brick element consisting the weighted average constraint element or RBE3. The RBE3 elements were employed to distribute and apply the load onto nodes, removing the infinite local stiffness when only applying the RBE2 element [41]. Due to that, the ACM2 element connectors can provide reasonable stiffness to the finite element model of the structure in the range of the frequency of interest. These characteristics make ACM2 element connectors much more convenient to be used in FE modelling of the laser stitch welded structure. Therefore, on the matter of modelling convenience and due to the abilities to represent the actual laser stitch welds due to brick element presentation, it suggests that the ACM2 element connector has the better capability, and is more appealing than the other three element connectors to represent the laser stitch welds.

Table 3. Comparison between measured and predicted natural frequencies of laser stitch welded structure.

\begin{tabular}{|c|c|c|c|c|c|c|c|c|c|}
\hline I & II & III & IV & V & VI & VII & VIII & IX & X \\
\hline \multirow[t]{2}{*}{ Mode } & $\begin{array}{l}\text { Measured } \\
(\mathrm{Hz})\end{array}$ & $\begin{array}{c}\text { ACM2 } \\
\text { Model } \\
(\mathrm{Hz})\end{array}$ & $\begin{array}{l}\text { Error } \\
(\%)\end{array}$ & $\begin{array}{c}\text { CQUAD } \\
\text { Model } \\
(\mathrm{Hz})\end{array}$ & $\begin{array}{c}\text { Error } \\
(\%)\end{array}$ & $\begin{array}{c}\text { CBAR } \\
\text { Model } \\
(\mathrm{Hz})\end{array}$ & $\begin{array}{l}\text { Error } \\
(\%)\end{array}$ & $\begin{array}{c}\text { RBE2 } \\
\text { Model } \\
(\mathrm{Hz})\end{array}$ & $\begin{array}{l}\text { Error } \\
(\%)\end{array}$ \\
\hline & & & II-III & & II-V & & II-VII & & II-IX \\
\hline 1 & 521.52 & 519.33 & 0.42 & 517.57 & 0.76 & 518.57 & 0.57 & 528.05 & 1.25 \\
\hline 2 & 591.17 & 556.07 & 5.94 & 548.31 & 7.25 & 552.09 & 6.61 & 593.57 & 0.41 \\
\hline 3 & 595.44 & 565.89 & 4.96 & 563.13 & 5.43 & 564.99 & 5.11 & 579.55 & 2.67 \\
\hline 4 & 674.67 & 618.15 & 8.38 & 609.14 & 9.71 & 615.45 & 8.78 & 664.25 & 1.54 \\
\hline 5 & 681.61 & 628.49 & 7.79 & 620.02 & 9.04 & 625.06 & 8.30 & 670.20 & 1.67 \\
\hline \multirow[t]{2}{*}{6} & 694.64 & 649.62 & 6.48 & 641.23 & 7.69 & 643.61 & 7.35 & 688.83 & 0.84 \\
\hline & Total error & & 33.97 & & 39.87 & & 36.71 & & 8.38 \\
\hline
\end{tabular}

As per the findings so far, ACM2 element connector was identified as an appropriate candidate for FE modelling of laser stitch welds. However, based on the MAC results in the Table 4 and the mode shapes in Table 5, it has been noted that initial ACM2 based FE model and the other three FE models did not perfectly predict the mode shapes of the laser stitch welded structure particularly in mode 3 , mode 4 , mode 5 and mode 6 , where MAC of the stated mode shapes were below 0.8. Basically, the degree of correlation between pairing mode shapes vectors originating from finite element model and experimental modal analysis can be identified by the MAC values. The MAC values are a scalar constant that ranges between 0 and 1 . The value 0 indicates that it is not in good correlation while value 1 indicates that it is in perfect correlation between two sets of vectors. However, for the complex jointed structure like laser stitch welded structure, the acceptable range for the mode shapes correlation is between 0.7 to 1 diagonally [42].

The finite element modelling involving weld joints has always been difficult due to of the existence of many local effects that emanates during welding process [43-45]. Furthermore, local effects such as geometrical irregularities, heat affected zone and residual stress are difficult to be incorporated in any FE modelling and thus might 
influence the result of the predicted dynamic behaviour. Therefore, to successfully predict the dynamic behaviour of the structure, the improvement of the initial ACM2 based FE model needs to continue by addressing all the local effects determined that may influence the results.

Table 4. MAC values of FE models.

\begin{tabular}{|c|c|c|c|c|}
\hline \multirow[b]{2}{*}{ Mode } & \multicolumn{4}{|c|}{ Modal Assurance Criterion (MAC) } \\
\hline & ACM2 & CQUAD & CBAR & RBE2 \\
\hline 1 & 0.90 & 0.88 & 0.85 & 0.88 \\
\hline 2 & 0.92 & 0.89 & 0.87 & 0.83 \\
\hline 3 & 0.55 & 0.55 & 0.54 & 0.53 \\
\hline 4 & 0.76 & 0.76 & 0.75 & 0.79 \\
\hline 5 & 0.72 & 0.73 & 0.70 & 0.74 \\
\hline 6 & 0.61 & 0.67 & 0.62 & 0.62 \\
\hline
\end{tabular}

Table 5. Comparison between measured and predicted mode shapes of laser stitch welded structure.

\begin{tabular}{cccc}
\hline $\begin{array}{c}\text { Measured mode } \\
\text { shape }\end{array}$ & ACM2 mode shape & $\begin{array}{c}\text { Measured mode } \\
\text { shape }\end{array}$ & ACM2 mode shape \\
\hline Mode 1 & Mode 1 & Mode 4 & Mode 5 \\
\hline Mode 2 & Mode 2 & Mode 5 & Mode 6 \\
\hline Mode 3 & Mode 3 & & \\
\hline
\end{tabular}

\section{CONCLUSION}

The first six dynamic behaviours of a laser stitch welded structure were investigated experimentally and numerically. The potential element connectors, namely ACM2, CBAR, CQUAD and RBE2 were used to represent laser stitch weld joints. The feasibility and accuracy of potential element connectors were quantified by comparing the finite element results with experimental data. This study has shown that the ACM2 element connectors are the most appropriate element connector that can be used to represent laser stitch welds in comparison to other proposed element connectors which are RBE2, CBAR and CQUAD4. Firstly, this is because the predicted result from the ACM2 based FE model does not present any mode swapping issue. Secondly, the ACM2 element connectors are able to cover the actual welded areas because the element connectors are based on brick element. Thirdly, the element connectors can be realised either for congruent or non-congruent meshes, making them more convenient to be used. In order to successfully predict the dynamic behaviour of structure, the improvement of the initial ACM2 based FE model can continue in the future by determining all the local effects that may influence the results. This work is crucial in minimising the discrepancies in the 
resulting natural frequencies and mode shapes of the structure. Furthermore, a systematic reconciliation method (such as finite element model updating method) can also be used to improve the correlation of the initial finite element model.

\section{ACKNOWLEDGEMENT}

The research has been funded by the Malaysian Ministry of Higher Education (MOHE) and Research Management Institute (RMI) of Universiti Teknologi MARA (UiTM) for the LESTARI Research Grant with the file number 600-IRMI/MyRA 5/3/LESTARI (088/2017). Besides, the authors would like to express their gratitude to the members of the Structural Dynamics Analysis and Validation (SDAV) UiTM for their technical assistance and laboratory facilities.

\section{REFERENCES}

[1] Amada Miyachi America I. Laser Welding Fundamentals. 1st ed. California: Amada Miyachi Americe, INC., 2015.

[2] Devarasiddappa D. Automotive Applications of Welding Technology - A Study. International Journal on Mechanical Engineering; 4.

[3] Han L, Young K, Hewitt R, et al. Advanced joining technologies for aluminium assembly for the automotive industry. Materials Research Innovations 2009; 105116.

[4] Zin MSM, Rani MNA, Yunus MA, et al. Frequency response function (FRF) based updating of a laser spot welded structure. In: AIP Conference Proceedings. 2018, p. 020055.

[5] Yusuf AI, Norliyati MA, Yunus MA, et al. Investigation of dynamic properties of elastomeric bearing components via modal analysis. Jurnal Teknologi 2015; 76: $17-21$.

[6] Mohd Zin MS, Abdul Rani MN, Yunus MA, et al. Modal and FRF based updating methods for the investigation of the dynamic behaviour of a plate. Journal of Mechanical Engineering 2017; 4: 175-189.

[7] Yunus MA, Rani MNA, Sani MSM, et al. Finite element model updating of riveted joints of simplified model aircraft structure. In: AIP Conference Proceedings. 2018, p. 20013.

[8] Rashid ASY, Ramli R, Haris SM, et al. Improving the dynamic characteristics of body-in-white structure using structural optimization. The Scientific World Journal 2014; 2014: 1-11.

[9] Zahari SN, Zakaria AAR, Sani M, et al. A review on model updating of joint structure for dynamic analysis purpose. In: MATEC Web of Conferences. EDP Sciences, 2016, p. 00023.

[10] Zhang J, Ouyang H, Yang J. A new direct method for updating mass and stiffness matrices with no spillover. Mechanisms and Machine Science 2015; 23: 609-618.

[11] Nishio M, Marin J, Fujino Y. Uncertainty quantification of the finite element model of existing bridges for dynamic analysis. Journal of Civil Structural Health Monitoring 2012; 2: 163-173.

[12] Langer P, Sepahvand K, Guist C, et al. Finite element modeling for structural dynamic analysis of bolted joints under uncertainty. Procedia Engineering 2017; 199: 954-959.

[13] Daouk S, Louf F, Dorival O, et al. Uncertainties in structural dynamics: overview 
and comparative analysis of methods. Mechanics \& Industry 2015; 16: 404.

[14] Husain NA, Khodaparast HH, Snaylam A, et al. Finite-element modelling and updating of laser spot weld joints in a top-hat structure for dynamic analysis. Journal of Mechanical Engineering 2010; 224: 851-860.

[15] Norhisham Abdul Rani M, Kasolang S, Hakimi Othman M, et al. Finite element modelling and modal based updating for the dynamic behaviour of a laser spot welded structure. In: ICSV 2016 - 23rd International Congress on Sound and Vibration: From Ancient to Modern Acoustics. International Institute of Acoustics and Vibrations, 2016.

[16] Yunus MA, Aziz Shah MAS, Rani MNA, et al. Experimental and finite element analysis of laser stitch welded structure. Journal of Mechanical Engineering.

[17] Nazri NA, Sani MSM. Finite element normal mode analysis of resistance welding jointed of dissimilar plate hat structure. In: IOP Conference Series: Materials Science and Engineering. 2017, p. 012059.

[18] Palmonella M, Friswell MI, Mottershead JE, et al. Guidelines for the implementation of the CWELD and ACM2 spot weld models in structural dynamics. Finite Elements in Analysis and Design 2004; 41: 193-210.

[19] Palmonella M, Friswell MI, Mottershead JE, et al. Finite element models of spot welds in structural dynamics: Review and updating. Computers and Structures 2005; 83: 648-661.

[20] Ha J, Huh H, An Y, et al. Compatible finite element modelling of laser welded region for crash analysis of autobody assemblies. Materials Research Innovations; 15. Epub ahead of print Feb 2011. doi: 10.1179/ 143307511X12858957675318.

[21] Piscan I, Predincea N, Pop N. Finite element analysis of bolted joint. Proceedings in Manufacturing Systems 2010; 5: 167-172.

[22] Somashekar VN, Harikrishnan S, Aejaz Ahmed PSM, et al. Vibration response prediction of the printed circuit boards using experimentally validated finite element model. Procedia Engineering 2016; 144: 576-583.

[23] Abd Halim. N.I, Yunus.M.A, Kasolang.S RMN. Finite element model of the spot welded joints of door in white (DIW). Engineering and Applied Sciences 2016; 11: 2474-2478.

[24] Hassin NM, Yunus MA, Radzi A, et al. Using updated model for the crash analysis. In: 23rd International Congress on Sound and Vibration 2016 (ICSV 23). 2016, p. 536.

[25] Ahmadian H, Gladwell GML, Ismail F. Parameter Selection Strategies in Finite Element Model Updating. Journal of Vibration and Acoustics 1997; 119: 37-45.

[26] Sehgal S, Kumar H. Structural dynamic model updating techniques: a state of the art review. Archives of Computational Methods in Engineering 2016; 23: 515533.

[27] Yunus MA, Ouyang H, Rani MNA, et al. Modal test and model updating for a welded structure made from thin steel sheets. In: 20th International Congress on Sound and Vibration 2013, ICSV 2013. 2013, pp. 7-11.

[28] Nuruzzaman M, Wu CQ, Ojo O. Modeling of welding joint using effective notch stress approach. In: International Mechanical Engineering Congress and Exposition. 2015, pp. 1-8.

[29] Hassin.N.M, Yunus.M.A, Abdul Rani.M.N SMS. Experimental and finite element analysis of riveted joints structure of a simplified model of aluminium crash box. Journal of Engineering and Applied Sciences 2016; 11: 1451-1455.

[30] Ahmad Basri AB, Abdul Rani MN, Yunus MA, et al. The investigation of dynamic 
behaviour of a structure using wave-based substructuring method. In: MATEC Web of Conferences. 2017, p. 01011.

[31] Avitabile P. Experimental modal analysis: a simple non-mathematical presentation. Sound and Vibration 2001; 1-11.

[32] Kranjc T, Slavić J, Boltežar M. A comparison of strain and classic experimental modal analysis. Journal of Vibration and Control 2016; 22: 371-381.

[33] Brown DL, Allemang RJ. The modern era of experimental modal analysis: one historical perspective. Sound \& Vibration 2007; 40: 16-25.

[34] Minardo A, Coscetta A, Pirozzi S, et al. Experimental modal analysis of an aluminum rectangular plate by use of the slope-assisted BOTDA method. Smart Materials and Structures; 22. Epub ahead of print 2013. DOI: 10.1088/09641726/22/12/125035.

[35] Sulaiman MSA, Yunus MA, Rani MNA, et al. Characterisation of the dynamic characteristics of a complex jointed structure. In: MATEC Web of Conferences. EDP Sciences, 2017.

[36] Yunus MA, Rani MNA, Ouyang H, et al. Identification of Damaged Spot Welds in a Complicated Joined Structure. Journal of Physics: Conference Series 2011; 305: 12057-12067.

[37] Saeed S, Farhad A. Effects of accelerometer mounting methods on quality of measured FRF's. In: The 21st International Congress on Sound and Vibration. 2014, pp. 13-17.

[38] Zin MSM, Rani MNA, Yunus MA, et al. Modal based updating for the dynamic behaviour of a car trunk lid. In: AIP Conference Proceedings. 2019, p. 020001.

[39] Ewins D. Modal Testing: Theory, practice, and application. 2nd ed. England: Research Studies Press Ltd., 2000.

[40] Fang J, Hoff C, Holman B, et al. Weld modeling with MSC . Nastran. In: MSC 2000 World Users' Conference Proceedings. 2000, pp. 1-14.

[41] Kuratani F, Okuyama M, Yamauchi T, et al. Finite element modeling of spot welds for vibration analysis. 5th Asian Conference on Multibody Dynamics.

[42] Allemang RJ. The modal assurance criterion - Twenty years of use and abuse. Journal of Sound and Vibration 2003; 37: 14-21.

[43] Mares C, Mottershead JE, Friswell MI. Stochastic model updating of a spot welded structure. In: International Conference on Noise and Vibration Engineering. 2005, pp. 1885-1898.

[44] Zhang H. Resistance welding: fundamentals and applications. 2006. Epub ahead of print 2006. DOI: 10.1017/CBO9781107415324.004.

[45] Saleem J, Majid A, Bertilsson K, et al. 3 Dimensional finite element simulation of seam welding process. Elektronika ir Elektrotechnika 2013; 19: 73-78. 